\title{
Refining a model for understanding and characterizing instructor pedagogy in informal physics learning environments
}

\author{
Michael B. Bennett and Brett Fiedler \\ JILA NSF Physics Frontier Center, 440 UCB, Boulder, Colorado 80309, USA \\ and Department of Physics, University of Colorado Boulder, Boulder, Colorado 80309, USA \\ Noah D. Finkelstein \\ Department of Physics, University of Colorado Boulder, Boulder, Colorado 80309, USA
}

(Received 17 June 2020; accepted 21 October 2020; published 20 November 2020)

\begin{abstract}
Public engagement is an important component of the operation of many physics organizations, such as physics departments. However, comparatively little work has been done to systematize the study of pedagogical approaches in these informal environments, which may contain unique affordances and challenges compared to formal settings. A 2016 study took an important step toward a comprehensive understanding of pedagogy in informal environments by developing a model articulating three so-called "modes of pedagogy," utilizing cultural-historical activity theory to categorize pedagogy of volunteer instructors. To build upon this model, we have conducted a more thorough study at a University of Colorado Boulder-based informal physics education program, following similar methods but expanding upon the methodology to generate more robust insights into instructors' pedagogy. The study has produced three major results. First, we have broadly corroborated the findings of the 2016 study, observing similar distributions of enacted pedagogical preferences among our volunteer instructors. Second, we have expanded upon recommendations in the 2016 study for methods of instructor preparation; specifically, we find that presemester training is insufficient to effect a lasting change in instructors' enacted pedagogy. Third, we have refined the pedagogical modes model presented in that work, moving away from a categorical articulation of the modes in favor of a model where instructors' pedagogy is characterized by combinations of traits and mediated by their overarching objectives for students. These two novel additions to the pedagogical modes framework allow for a more nuanced and comprehensive characterization of the pedagogical techniques used by instructors in informal learning environments, improving both our understanding of the methods of informal pedagogy and our ability to prepare instructors to succeed.
\end{abstract}

DOI: 10.1103/PhysRevPhysEducRes.16.020137

\section{INTRODUCTION}

Informal physics education, more commonly known in the physics community as "outreach," is undertaken by a number of organizations in the United States. Both the American Physical Society (APS) and the National Science Foundation (NSF) have articulated participation and outreach-related goals and initiatives as part of their respective missions [1,2]. Informal experiences, especially those prior to high school, have been well documented to serve as catalysts for would-be scientists' interest in joining the professional scientific community $[3,4]$. Indeed, the NSF's broader impacts criterion explicitly ties community

Published by the American Physical Society under the terms of the Creative Commons Attribution 4.0 International license. Further distribution of this work must maintain attribution to the author(s) and the published article's title, journal citation, and DOI. engagement components, such as increased participation of groups historically underrepresented in the physical sciences, to the success of science, technology, engineering, and math (STEM) research grants. Physics departments therefore frequently leverage informal education efforts towards their research goals, as well as to connect with and inform community members, generate excitement for and interest in physics, and promote development of physics identity. An additional attribute of informal physics education programs is their ability to support the development of university-based participants and, potentially, even advance the institutions themselves. For example, informal learning programs have been linked with classes where students learn formal education theory and practice to complement their volunteer pedagogical experience [5].

Informal learning presents a number of unique challenges and opportunities when compared to formal learning. Outreach environments often prioritize participant enjoyment and interest, rather than other traditional 
learning goals such as content acquisition, as this emphasis can lower barriers to engagement that may exist for participants. In such environments, learners may more easily engage in forms of learning that go beyond simple content acquisition, such as reflecting on the epistemology of physics or developing an identity as a physicist. These and other strands are articulated by the National Academy of Science, for example [6]. Participants also often have increased opportunities to exhibit agency, choosing the means of their engagement and engaging in more inquirybased learning. Taken as a whole, these facets of outreach often mean that informal education can have an outsized impact on participants' engagement with STEM or even their long-term STEM affiliation [3]. However, this focus on flexibility and participant agency also means that students are more likely to participate for a variety of reasons and with a variety of objectives in mind, making it comparably difficult to answer questions of productivity in the same manner as in a formal setting such as a classroom.

Similarly, the question of "effective pedagogy" in informal environments is not simple to answer. For many physics departments, outreach is often facilitated by undergraduate and graduate students. These instructors typically receive training in formal environments, such as teaching assistant (TA) or learning assistant (LA) programs $[7,8]$ and are trained in pedagogical techniques, such as tutorial facilitation, addressing misconceptions, and Socratic dialogue, which are well adapted to those environments [9-11]. These techniques are often the result of dedicated, rigorous research-based design. Comparatively little work has been done in the physics community, however, researching effective pedagogical practices in informal environments, where, again, content mastery is rarely as heavily prioritized as in formal settings. Naturally, studies and interventions predicated upon the primary goal of content acquisition, as is common in study of formal spaces, may not be applicable in informal settings.

\section{A. Rationale for study}

In 2016, Hinko et al. published a study on pedagogical practices in informal physics education environments. That work laid out a framework that described the pedagogical methods of volunteer instructors in one informal education environ, finding that instructors' pedagogy tended to fall into one of three "modes of pedagogy," techniques that could be adopted as needed by volunteers and leveraged toward meeting the pedagogical goals of the informal program [12]. A full description and discussion of these pedagogical modes is presented in Sec. II D 1, but, briefly, the three modes as articulated by Hinko are as follows: instruction mode, wherein the instructor takes a "lecturelike" approach to pedagogy, leading students toward content knowledge similar to a traditional classroom; consultation mode, wherein the instructor takes an "advice-like" approach, supporting student engagement from the side without taking control; and participation mode, wherein the instructor takes a more "partner-like" approach to pedagogy, working alongside students as equals toward shared goals and engagement.

Hinko's 2016 work found that instructors tended to exhibit preferences between these modes that persisted throughout the semester. That is, instructors tended not to shift between modes or engage in mixed-mode teaching in either the short term (e.g., over a single day of pedagogy) or the long term (e.g., over the course of the semester). The study also observed a difference of implementation between two instructors engaged in the consultation mode, which Hinko attributed to differences in the instructors' overarching objectives for pedagogy: either “... helping [the] group in the pursuit and achievement of a specific scientific task," or "students to explore and test possible variations in the activity." [12]. In the conclusion of her work, Hinko argued that exposure to the modes ought to be incorporated into the pedagogical preparation of volunteer instructors, in part to help instructors utilize the modes as tools when enacting their various objectives.

To build upon the successes of that study and make further inroads to understand, describe, and, ultimately, improve pedagogical techniques in informal settings, we have conducted an in-depth follow-up study of volunteer instructors' utilization of the pedagogical modes in a University of Colorado-based informal physics education program. In line with the recommendations of Ref. [12], we implemented training modules in pre-semester preparation explicitly familiarizing volunteers with the modes as pedagogical techniques. We then observed pedagogy over the course of the semester with an eye toward volunteers' choices among the pedagogical mode. Broadly, the results of our study corroborate the findings originally reported in Ref. [12] with respect to the utilization of and preference among the modes in our volunteers' pedagogy. However, we extend that work in a few major ways. First, we find that such training, as recommended in Ref. [12], is effective for making our volunteers aware of the pedagogical stances [13] but likely insufficient for aligning instructors' enacted preferences, as observed during their teaching, with their stated preferences among, or even their understandings of, the modes. Second, we observed novel pedagogy that blended modes, an outcome not discussed in Ref. [12]. Third, we expand the model to consider broader drivers and objectives that are alluded to by Hinko, associating these objectives with the choices instructors make to employ the pedagogical modes. Using these findings as a starting point, we ultimately construct a refined model of volunteers' pedagogy that takes into account not only their moment-to-moment pedagogical techniques but also their overarching objectives for activity.

The major contributions of the present work are thus as follows: (i) a corroboration of Hinko's 2016 work observing and articulating the modes; (ii) an expansion upon 
Hinko's recommendations for instructor preparation, specifically the insufficiency of simply exposing volunteers to and training them in the modes prior to engaging in pedagogy; (iii) an expansion of the pedagogical modes model to incorporate rationale for the observance of mixed modes and a more robust conception of the ways in which instructors' objectives may influence their choice of pedagogical mode. In this work we will report upon these findings, articulate the new model, and lay the groundwork for future studies investigating the factors that influence volunteer pedagogy and, potentially, lead to dissonance between their stated and enacted beliefs.

\section{STUDY CONTEXT}

\section{A. The Partnerships for Informal Science Education in the Community program}

The context for this study is, as mentioned above, an informal physics education program based at the University of Colorado Boulder (CU Boulder). This program, the Partnerships for Informal Science Education in the Community (PISEC), was created as a joint effort between the CU Boulder physics education research (PER) group and the JILA NSF Physics Frontier Center (PFC) [14-16]. Since its inception, PISEC has worked to partner with local Colorado schools and community members to provide opportunities for students, especially those historically underrepresented in the physics community, to explore physics through open-ended, inquiry-based physics content. PISEC works with $\mathrm{K}-12$ students, primarily students in grades 4-7 and in high school. On average, the population of PISEC students is more than 50\% from groups historically underrepresented in STEM, predominantly Latinx, and more than $50 \%$ from lower socioeconomic status groups.

PISEC is based on the highly successful book Fifth Dimension (5D) model of afterschool programming [17]. The model is predicated upon a sociocultural perspective of learning first articulated by Vygotsky [18]. Particularly salient to 5D and to PISEC is the notion that an individual's cognitive development is mediated by the tools used by that individual and the community in which they participate. In the case of PISEC, the program utilizes volunteer instructors, known as "university educators" (UEs) in order to help facilitate students' engagement with physics tools and techniques, creating a shared cultural experience (similar in conception to the notion of "third spaces" $[19,20])$ that empowers students to take ownership over their participation in the physics enterprise. By centering both the student and mentor experience on this shared inquiry, PISEC hopes to encourage students to engage in essential components of scientific behavior while maintaining their unique perspectives-and, indeed, even influencing those of their mentors. In this way, the program seeks to normalize STEM community participation for students from underrepresented groups and incorporate a more diverse perspective into STEM culture, creating a more equitable landscape in the process.

Another facet of 5D design is the idea of collaborative work that benefits multiple groups of participants, rather than establishing a hierarchy where some participants "serve" the needs of others. In 5D programs such as PISEC, systems are designed intentionally to provide benefit to multiple stakeholders, including both the $\mathrm{K}-12$ students and the university-based mentors. Additionally, the intent is that these participants, upon returning to engage with their respective "origin" communities, would become agents of positive impact on an institutional or cultural level. In this way, PISEC also hopes to impact, for example, the way in which the JILA PFC, which houses PISEC, views public engagement as a component of professional physics activity. Like many public engagement programs, PISEC works to provide benefit to student participants through affective gains, skill acquisition, content learning, etc., [21-23]. Much care has also been taken, however, to provide occasion as well for PISEC's UE mentors to develop their public speaking and science communication skills, expand their worldview about the place of public engagement within the scientific enterprise, and-most saliently for the present work-gain and improve pedagogical skills that are applicable in a variety of contexts $[24,25]$.

\section{B. Pedagogy in PISEC and the role of the UE}

The present work details an investigation of pedagogy in PISEC's primary-school branch. PISEC takes the form of a weekly afterschool program implemented at several partner sites. Each week, for 10 weeks of the semester, 5-10 UEs travel, along with a site leader (typically an experienced PISEC UE who has applied for this leadership position) to a specific partner primary-school site. PISEC currently supports three separate primary-school partner sites; it thus engages the services of approximately 20-25 UEs for the purpose of visiting these sites each semester.

Each week, 20-30 primary-school students participate at each partner site. Students typically attend most, if not all, of the program's 10 weekly sessions, and see their UE mentors week after week. During these weekly sessions, students engage in open-ended physics activities that span a variety of topics. These activities present students with foundations upon which they can design their own experiments in pursuit of answers to the science questions posed by prompts included as part of the activities. These activities are designed to foster experimentation and exploration rather than simply attention to content; previous work has detailed design and implementation of this format and reported on the effect on students' agency, communication skills, and mechanistic reasoning [21,22].

The role of the UE in this format is that of a facilitator and experienced peer mentor. UEs draw on their disciplinebased expertise (i.e., their relative mastery of physics 
content and scientific process) to encourage students along fruitful avenues of inquiry, both helping them articulate questions and form strategies for investigation. UEs also demonstrate and model expertlike physics engagement in a way that appeals to students' potential interest in STEM. Because of UEs' relative STEM mastery, they are able to help students interpret their experiments, co-constructing productive pathways through the curriculum. For example, consider a situation where students express interest in a specific activity such as investigating the drag of a parachute (perhaps, as is common, because they are drawn toward the materials used in that activity, such as plastic parachute toys), but hesitate to begin the activity (perhaps because they do not fully understand the nature of the prompt or the question it poses, such as the facets of surface area and timing that impact a parachute's behavior). In this situation a UE may engage in a shared sense making with the students (similar to a Teaching Assistant or Learning Assistant), proposing their own ideas for experimentation for the group to consider, helping interpret the prompt, etc. The UE may suggest for example that the students throw the parachute toys into the air vs dropping them from rest at the same height. Such activity helps normalize the notion that students and their UE mentors are collaborators, building science culture together, and maintains students' overall agency in directing their engagement with PISEC.

As students and their UE mentors progress through the semester together, UEs have continued opportunities to engage in this facilitative pedagogy. Students continue to engage in increasingly more sophisticated activities, design their own experiments (including, occasionally, experiments beyond the scope of the curriculum), practice their scientific writing, etc. UEs, again because of their discipline-based expertise, help the students navigate these components of the scientific process while also helping students acclimate to the idea of being or becoming a fellow scientist. Because PISEC puts so much emphasis on the development of this shared culture, it is very common for students and their mentors to develop close bonds; for example, students often inquire about their UEs' health and status when UEs are absent from site visits.

\section{UE pedagogical preparation}

While UEs' discipline-based experience supports to their ability to engage students with the scientific process and the physics enterprise, most UEs do not have formal training in pedagogy to the degree that, for example, teaching-track education students receive. Many UEs do have some experience in formal pedagogy situations, such as TA or LA training, but few have meaningful training in informal pedagogical or public engagement techniques, much less in the more affective and relational techniques utilized in 5D programs and in PISEC.

To that end, UEs undergo approximately $5 \mathrm{~h}$ of preparatory training at the start of each semester, prior to any site visits. UEs are exposed to the philosophies and unique facets of informal learning, inquiry-based education, etc., $[6,18,26]$. They are also given opportunity to discuss the demographics of their sites (as mentioned above, PISEC sites are typically $\geq 50 \%$ Latinx, as compared to $\mathrm{CU}$ Boulder's reported 12\% Latinx enrollment [27]) and engage with PISEC's equity-focused components through facilitated discussion based on equity-oriented activities and research by other investigators on the lived experiences of minorities in STEM communities. The discussion aims to confront potential UE assumptions about student abilities (especially as members of underrepresented groups, compared to the largely white CU Boulder population) $[28,29]$, to demonstrate and deconstruct potentially harmful ways of thinking about and conducting STEM education [30], etc.

Finally, they are exposed to the various pedagogical tools, techniques, and structures implemented at PISEC sites and given opportunity to practice with the curricula they will implement throughout the semester and to discuss scenarios that could occur throughout the semester viz. students' engagement with the PISEC curricula. Starting in the fall semester of 2016, we began implementing training on the pedagogical modes listed above and articulated below. The implementation of that training and findings from preliminary studies on its effects on volunteers is discussed in Sec. II D 2.

Throughout the entirety of their preparation, and repeatedly throughout the semester, UEs are encouraged to see themselves not exclusively as "instructors" in a traditional sense but more as coaches, mentors, facilitators, or partners to the students. Students' positive engagement with STEM is centralized and prioritized over content knowledge in messaging during and after training; this is intended both to maintain adherence to PISEC's affective goals and to reduce the probability that UEs will revert to "traditional" teacher-student dynamics in their execution of their pedagogical duties. Throughout PISEC's lifetime, a number of studies have been undertaken to investigate the ways in which UEs' participation in PISEC and their exposure to this paradigm of pedagogy influence their communication skills, motivations for participating in public engagement, and understanding of the role of outreach in physics $[23-25,31]$.

\section{Prior work}

\section{Pedagogical modes of UES}

To complement work investigating the outcomes of PISEC participation on UEs, Hinko et al. published in 2016 a study investigating the implementation of their pedagogy in PISEC [12]. As mentioned above, the major result of that work was the articulation of three major "modes of pedagogy": specific, divergent styles of pedagogy adopted by UEs throughout their engagement with students in PISEC's primary-focused afterschool 


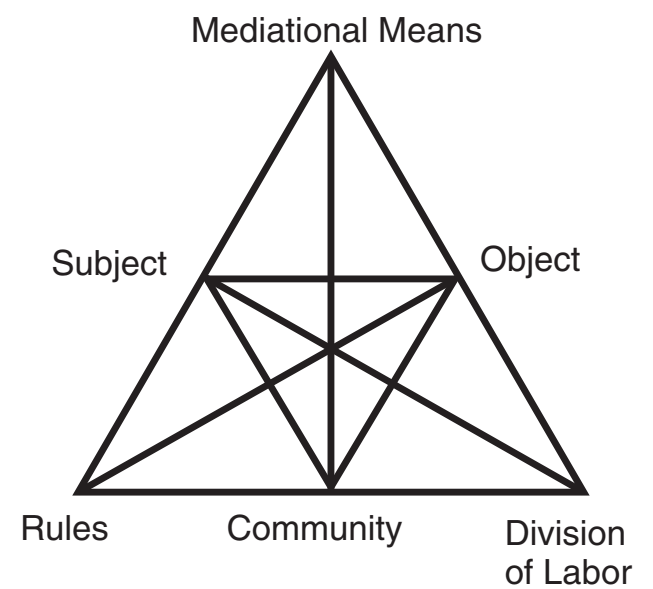

FIG. 1. Generalized cultural-historical activity triangle, as used in Refs. [12,33,37], and this work. Lines between each aspect of the triangle indicate interactions that mediate the activity of the subject either directly or indirectly.

program. Hinko utilized cultural-historical activity theory [(CHAT) - see Fig. 1 for a depiction of the elements and Sec. III B for a full description of the theory as used in this work], derived from principles of Vygotsky's work and refined by Leont'ev, Engeström, and others [18,32-36], to differentiate three modalities-instruction, consultation, participation-based on their CHAT characteristics (we discuss CHAT in detail in Sec. III B; Fig. 1 articulates the different characteristics of CHAT, such as division of labor, used to articulate the modes in Ref. [12] and here). While the reader is encouraged to consult the text of Ref. [12] for the full description of that study and its results, we here briefly summarize the pedagogical modes, as the present work utilizes the modes in its analysis and expands upon those results.

Instruction mode: Hinko identified the instruction mode by characteristics "... similar to those of a traditional, teacher-centered classroom setting." UEs in instruction mode as defined by Hinko direct their activity toward promoting content learning in their students, utilizing lecturelike methods to teach students. The UE maintains control over the curriculum equipment, and holds a position of authority within the group's division of labor; students may orient their bodies toward the UE, pose their questions to the UE rather than to one another, etc. The UE may provide affirmation to students after appearing to meet content- or knowledge-related acquisition goals. While, as noted above, UEs are encouraged not to frame themselves exclusively as traditional lecturelike "instructors," Hinko noted that this mode can indeed be leveraged toward achieving PISEC's goals, for example, through the provision of encouragement by the UE to students.

Consultation mode: Hinko characterized the consultation mode according, in large part, to the positioning of the UE relative to the students within the group's division of labor. In consultation mode, “... UEs do not give direct explanations but instead make comments and suggestions on students' activity, acting as more of an advisor to the group." Where in instruction mode, the UE retains control of the experiment, here students have primary control of any experimental equipment and direct questions primarily to one another as well, rather than to the UE, although they may ask the UE for advice or support or praise. In this mode, according to Hinko, UEs direct their activity toward students' engagement and exploration. As discussed above, Hinko also reported two different implementations of consultation mode, seemingly mediated by UEs' different apparent scientific objectives for student engagement: one focused on student engagement and one focused on "productive" adherence to the activity prompt.

In the previous study, a majority of UE pedagogy fell into this mode - approximately $60 \%$ of observed pedagogy in Hinko's study was categorized as consultation mode.

Participation mode: In participation mode, as characterized by Hinko, UEs direct their activity toward shared exploration of the experiment so as to facilitate engagement. Here, in contrast to the physics-knowledge orientation of instruction mode or exploration orientation of consultation mode, the UE works to collaborate with students, sharing in both experimentation and play. UEs and their students share control, ownership, and responsibility for the experiment and, as Hinko notes, "both UEs and students manipulate equipment and make measurements." Notably, Hinko observed that participation mode, more than the other two modes, downplays the importance of the curriculum prompts in favor of (even unstructured) experimentation.

In using CHAT to describe and define the pedagogical modes, Hinko argued that the primary differentiating factors between them were the activity system's division of labor, denoting how different agents within the group behave (for example, as described above with respect to the UEs' role in the group's engagement with content), and the group's rules, which describe how the group members engage with nonagent aspects of the system (for example, answering questions like "when does the group consult their curriculum prompt?"). As Hinko described, “... the 'explicit norms and conventions' [36] of interaction within a group vary depending upon the mode." In comparison, Hinko found that the CHAT aspects of community (the agents acting within the group system) and mediational means (the tools and artifacts used and created by the group members during activity) are held constant among the pedagogical modes. For example, most groups, regardless of the mode employed by the UE, tend to utilize the curriculum prompt as a starting point and employ the experiment's equipment in their activity.

In Hinko's work, the three pedagogical modes are articulated categorically; that is, they are described as mutually exclusive, with each mode being defined in its 


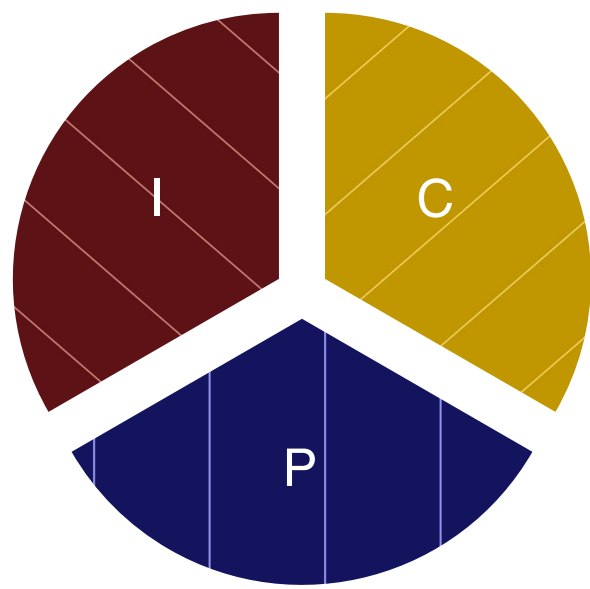

FIG. 2. A depiction of the three pedagogical modes articulated by Hinko in Ref. [12]. Each mode, defined categorically by its CHAT elements, is separate from each other mode.

entirety by the set of CHAT elements (Fig. 1) ascribed to it. We have included Table I as a reproduction of Hinko's description of the pedagogical modes and the respective CHAT elements of each mode as articulated in Ref. [12], and Fig. 2 as a depiction of the original model.

Two additional findings from the report of Ref. [12] are relevant to the present discussion. First, Hinko made an inference between observations of UEs' enacted pedagogical modes and their "science objectives, or science learning goals for students." In that paper, Hinko demonstrated instances where two UEs, both engaged in a consultationlike pedagogy, evidenced divergent overarching objectives for student engagement. Hinko articulated these divergent objectives as "helping [the] students in the pursuit and achievement of a specific scientific task" (emphasis added) and as helping students "explore and test possible variations in the activity" (emphasis added). These "outcome-oriented" and "process-oriented" (our terms) manifestations of consultation mode were used by Hinko to argue for the possibility that nonemergent factors, such as UE objective, may mediate a UE's enactment of the modes. Second, Hinko concluded that all three modes of UE pedagogy may be leveraged toward accomplishing PISEC's goals. As Hinko notes, “... we do not observe a hierarchy of modes that are either 'good' or 'bad' at achieving these goals. Instead, each modality has both affordances and limitations and may be more or less suitable depending on local circumstances."

Hinko recommended that UEs treat the modes as pedagogical tools, techniques to be picked up and set down when beneficial. To facilitate a technique-driven framing of the modes and their uptake as pedagogical tools, Hinko recommended that PISEC include explicit orientation and preparation on the modes as part of its UE preparation - this recommendation was the impetus for the aforementioned modification in UE training that formed the basis for this study.

\section{UE preparation and modal preferences}

In Fall 2016, we began to implement training on the modes in our presemester UE preparation sessions. Our modified preparation sessions implemented two novel components based on Hinko's recommendations. First, UEs were presented with definitions and characteristics

TABLE I. Comparison of CHAT elements of the three pedagogical modes, as articulated in Ref. [12]. In the 2016 model, each mode is defined categorically and with mutual exclusion by its associated CHAT elements.

\begin{tabular}{|c|c|c|c|}
\hline & Instruction & Consultation & Participation \\
\hline Subject & UE & UE & UE \\
\hline Object & $\begin{array}{l}\text { Conveying physics knowledge to } \\
\text { students }\end{array}$ & $\begin{array}{l}\text { Allowing students to come to an } \\
\text { understanding of the material and } \\
\text { develop independent reasoning skills }\end{array}$ & $\begin{array}{l}\text { Sharing in the activity so as to engage } \\
\text { students. }\end{array}$ \\
\hline Rules & $\begin{array}{l}\text { UE talks, students listen and } \\
\text { follow instructions from UE and } \\
\text { activity prompts. Curriculum } \\
\text { and UE guide activity. }\end{array}$ & $\begin{array}{l}\text { UE responds to students' explicit (or } \\
\text { implicit) questions. Both UEs and } \\
\text { students follow curricular prompts. }\end{array}$ & $\begin{array}{l}\text { Experiment and observations } \\
\text { determines [sic] outcomes or } \\
\text { answers. All participants ask and } \\
\text { answer questions. Joint construction } \\
\text { of activity by UEs and students. }\end{array}$ \\
\hline Community & Students and UEs & Students and UEs & Students and UEs \\
\hline $\begin{array}{l}\text { Division of } \\
\text { labor }\end{array}$ & $\begin{array}{l}\text { Students conduct experiments. } \\
\text { UE acts as authority figure, } \\
\text { gives directions, and answers } \\
\text { questions explicitly. Students } \\
\text { write in their notebooks. }\end{array}$ & $\begin{array}{l}\text { Students conduct experiments. } \\
\text { UE observes and responds to } \\
\text { difficulties or questions, knowing } \\
\text { answer and outcomes. Students write } \\
\text { in notebooks. }\end{array}$ & $\begin{array}{l}\text { Students and UEs collaborate, sharing } \\
\text { responsibility for conducting } \\
\text { experiments. UE models equipment } \\
\text { use. Students write in notebooks. }\end{array}$ \\
\hline $\begin{array}{l}\text { Mediational } \\
\text { means }\end{array}$ & $\begin{array}{l}\text { Conveying physics knowledge to } \\
\text { students }\end{array}$ & $\begin{array}{l}\text { Allowing students to come to an } \\
\text { understanding of the material and } \\
\text { develop independent reasoning skills }\end{array}$ & $\begin{array}{l}\text { Sharing in the activity so as to engage } \\
\text { students. }\end{array}$ \\
\hline
\end{tabular}


of the modes, following their CHAT-based articulations in Ref. [12]. Second, UEs were given opportunity to practice all three of the modes in group roleplay scenarios with other UEs, acting in sequence as both instructor and student, using real PISEC activities.

In the first two semesters during which we implemented this modified training, we conducted a preliminary study of its effects on UEs' stated preferences among the modes. In that study, we surveyed UEs before training (that is, before they had been exposed to the modes) and afterward [13]. From their pretraining survey responses, we inferred their implicit pedagogical preferences and compared them to their explicitly stated posttraining preferences. The results of that study suggested that, prior to training, UEs' preferences aligned closely with Hinko's observed enacted preferences (i.e., similar proportions of preferences between instruction, consultation, and participation mode). Posttraining, UEs' stated preferences shifted toward a more "active" distribution, weighted more heavily toward participation mode. The questions we asked in our surveys of the UEs are described both in Ref. [13] and below in Sec. III A 1. This pilot study also surveyed UEs at the end of the semester, after having engaged in teaching for a semester; interestingly, findings suggested that UEs' stated preferences had "reverted" to resemble the presemester distribution. A second preliminary study building upon this groundwork looked at some of the factors that may influence the choices UEs make while teaching in PISEC [38]. This study found that UEs' expectations of PISEC, and of teaching in general, likely influence their pedagogical choices on a number of levels; these expectations likely play a role in UEs' enacted preferences among the pedagogical modes.

The present work represents an in-depth look at UEs' enacted pedagogical preferences: motivated by the findings and recommendations of Ref. [12], we utilized a similar study methodology to analyze both the ways in which UEs utilize the modes themselves in their PISEC teaching and how they operationalize knowledge of the modes gained from our presemester training session.

\section{STUDY METHODOLOGY}

The present work uses the methodology of the study of Ref. [12] as a basis, building on the data collection and analysis methods in that study to construct an improved picture of UE pedagogy in PISEC.

\section{A. Data collection methods}

\section{Surveys}

As in the preliminary study of Ref. [13], we performed presemester surveys before and after training and postsemester surveys after UEs completed their teaching in order to determine UEs' disposition toward the various pedagogical modes, any effects of their participation in training, and the "end point" of their pedagogical preferences after the semester. For the presemester, pre-training survey, we were naturally unable to ask all UEs directly about their preference between the pedagogical modes, as they had not yet been exposed to the modes. Instead, we asked them: "What do you consider to be your philosophy, style, approach to teaching?" From the ways in which they positioned themselves relative to students and situated the locus of agency for learning in their answers, we inferred their preferences among the modes. The posttraining and postsemester surveys explicitly asked UEs to express a preference among the modes. As reported in Ref. [13], a survey of the population of UEs on their pedagogical preferences among the modes revealed a statistically significant pre-post-training shift in modal preferences; the UEs chosen for this study were among those who demonstrated a shift similar to this before and after training. More details on the design and implementation of these surveys, as well as the findings of that preliminary study, can be found in Ref. [13]

\section{In situ video}

From among those UEs who exhibited a change in modal preference (for example, a shift from a solo preference for instruction mode to a joint consultation-participation preference), we selected six for deeper study. We gave these six UEs pseudonyms in our analysis and followed them throughout the semester, collecting in situ video and audio recordings of their teaching in PISEC from the beginning of the semester (weeks 1-3), middle of the semester (weeks 4-6), and end of the semester (weeks 7-10). In all, we collected 18 total videos, three per UE, each spanning the entirety of the $1 \mathrm{~h}$-long site visits, totaling approximately $12 \mathrm{~h}$ of video.

Each video was scanned for instances of UE pedagogy; we defined clear "start" and "stop" criteria and utilized these definitions to select from each video a series of pedagogy "events"; on average each video contained 7 such events. We defined an event similarly to the definition in Ref. [12] of "rich segments": segments of video where the UE is engaged with the activity and the students, and is performing some sort of pedagogical maneuver, or appears to be acting with pedagogical intent. The start and stop criteria we utilized are

\section{"Start" criteria:}

- The UE, unengaged, begins to engage with the students and/or the activity. For example, the UE, after chatting with students about their weekends, begins to talk about the experiment.

- The UE makes a statement, asks a question, or performs a pedagogical maneuver that lends the moment a new strain of engagement. For example, after a period where students are silently writing in their journals without input from the UE, the UE prompts 
the students for their ideas about the experiment and what they have learned.

- The UE makes a statement, asks a question, or performs a pedagogical maneuver that prompts students to engage with the activity in a new direction. For example, after a period where students are silently engaged with the activity without input from the UE, the UE asks the students what the group should try now, or suggests a new activity.

\section{"Stop" criteria:}

- The UE disengages from the activity for more than a few seconds (i.e., long enough that it appears evident that they have stopped engaging with either the experiment or the students).

- The UE makes a statement, asks a question, or performs a pedagogical maneuver that lends the moment "finality." For example, while the students are engaged with the activity, the UE instructs the students to write down their findings in their journals.

In situations where the UE engaged in start activity in rapid succession, e.g., where the UE attempted to commence student engagement but took a few tries before the UEs' prompting "sticks," we opted to start the event at the first instance of the UE's attempt to begin engagement. Similarly, we occasionally opted not to stop the event in situations where (a) the UE very clearly intended to restart engagement momentarily (e.g., the UE got up to grab equipment for the group to use) and (b) the UE's observed reengagement was clearly premeditated and a continuation of the UE's previous pedagogy, rather than the UE being "drawn in" by the students or deciding to implement a new pedagogical tactic. We collected, in total, 129 unique pedagogical events across the six UEs we followed over the course of the semester. The specific number of events observed for each UE is reported in Table II.

The intent behind these criteria for delineating pedagogical events was to centralize the UE's activity in both data collection and analysis; that is, we attempted as much as possible to take our cues from the UE as far as what the UE perceived as "teachable moments." We recorded these events according to these criteria whenever they occurred, unless the event was so short as to preclude a confident assessment of the UE's enacted pedagogical mode for the event (typically, these aborted events were less than $30 \mathrm{sec}$ ). Naturally, not every engagement between the UEs and the student met the criteria for a pedagogical event; we did not conduct express analysis on such interactions, or on interactions - pedagogical or not-which did not contain enough content to be confidently considered a pedagogical event per the criteria above. We noted 12 such aborted events across our dataset.

We made a note of, but did not include in our modal analysis, incidents where the interaction between the UE and students was exclusively nonscientific in nature. PISEC often promotes a blending of social and scientific aspects, in line with the knowledge that students typically come into the program with varying priorities [39]. While we believe that such nonscientific moments are inherently valuable, and made a note when such strictly social interactions occurred (9 times across our dataset), they do not meet the criteria above in defining events, and so were excluded from this formal analysis. In a similar vein, there were times in pedagogical events where "outside" agents (e.g., other UEs, the program director, other students, etc.) broke in to the group's activity. We typically did not modify our analysis for these moments of "interference" unless it was clear that the UE's pedagogical engagement with the outside agent caused a meaningful disruption to the UE's pedagogy. For example, in a situation where the program director walks by and leans into the group to ask a few questions, and the UE and students both engage to answer those questions, then turn back to their own activity and the director walks away, we did not modify our analysis. In the same situation where, instead, the UE

TABLE II. Summary of the stated (surveyed) and enacted preferences of the six UEs who are the focus of this study. The number, $n$, of pedagogical moments collected and analyzed for each UE is listed. The letters $I, C, P$ denote the instruction, consultation, and participation modes, respectively. Instances of a single letter denote a solo-modal preference. Combinations of one or more letters denote a preference, either stated or observed in enacted pedagogy, for multiple modes. Where shared preferences are reported in the survey, a UE gave either explicit or implicit preference. Where shared preferences are reported in observation, CHAT analysis resulted in an assignment of multiple modes within the same teaching event.

\begin{tabular}{|c|c|c|c|c|c|c|c|c|c|c|c|}
\hline \multirow[b]{2}{*}{ Pseudonym } & \multicolumn{3}{|c|}{ Survey preferences } & & \multicolumn{7}{|c|}{ Enacted preferences } \\
\hline & Pretraining & Post-training & Postsemester & & I & IC & $\mathrm{C}$ & $\mathrm{CP}$ & $\mathrm{P}$ & IP & ICP \\
\hline Angela $(n=20)$ & $\mathrm{C}$ & $\mathrm{CP}$ & $\mathrm{CP}$ & & 3 & 0 & 13 & 1 & 3 & 0 & 0 \\
\hline Gabriel $(n=26)$ & $\mathrm{C}$ & $\mathrm{P}$ & $\mathrm{CP}$ & & 1 & 0 & 17 & 3 & 5 & 0 & 0 \\
\hline Moira $(n=28)$ & $\mathrm{P}$ & ICP & $\mathrm{C}$ & & 3 & 0 & 18 & 4 & 3 & 0 & 0 \\
\hline Jesse $(n=20)$ & $\mathrm{I}$ & $\mathrm{C}$ & - & & 3 & 1 & 4 & 3 & 8 & 1 & 0 \\
\hline Jack $(n=14)$ & IC & $\mathrm{P}$ & $\mathrm{C}$ & & 0 & 5 & 3 & 2 & 4 & 0 & 0 \\
\hline \multirow[t]{3}{*}{ Winston $(n=21)$} & $\mathrm{C}$ & ICP & $\mathrm{P}$ & & 1 & 4 & 13 & 1 & 1 & 1 & 0 \\
\hline & & & & & I & IC & $\mathrm{C}$ & $\mathrm{CP}$ & $\mathrm{P}$ & IP & $\mathrm{ICP}$ \\
\hline & & & & Totals & 11 & 10 & 68 & 14 & 24 & 2 & 0 \\
\hline
\end{tabular}


alone responds to the director's inquiry, leaving the students to continue their work alone for more than a few seconds, we considered the UE's engagement in the moment to have ended and stopped analysis.

To determine the enacted pedagogical preferences of these UEs, we employed a method similar to that of the study in Ref. [12], utilizing cultural-historical activity theory (CHAT) to identify the activity characteristics of the UE's pedagogy. From this CHAT analysis, we categorized each pedagogical event according to the pedagogical mode or modes enacted by the UE during the event. We describe in more detail our utilization of CHAT analysis in Sec. III B. After categorizing each of the 129 pedagogical events among the pedagogical modes, we aggregated the statistics on UEs' enacted pedagogical preferences for comparison both among UEs and between UEs' stated pre-semester pedagogical preferences.

One important distinction between our study and the study of Ref. [12] concerns the "grain size" of the pedagogical events analyzed using CHAT (see Sec. III B). Where we take a more granular, "microgenetic" approach as detailed here, treating each pedagogical event as an isolated data point with its own pedagogical traits to be analyzed, Hinko analyzed what she called "interactions," which were defined more broadly, including the entirety of the UE's engagement with the students in the PISEC activity and spanning a broader time frame (Hinko analyzed 33 of these larger-scale interactions across $10 \mathrm{UEs}$ ). While we do not see either approach as necessarily better or worse than the other, we note the distinction here because of the probability that some of our observational findings (particularly our observation of mixed-modal pedagogy, detailed in Sec. IV) stem from these methodological differences. We leave a detailed discussion of these differences for Sec. V B and only note the distinction here.

\section{Interviews}

To gain deeper insight into the factors that influence UEs' pedagogical choices as well as their beliefs and attitudes about teaching in PISEC, we also conducted semistructured interviews with three of the six UEs studied. These interviews contained three main components: (i) we asked the UE general questions about their participation in PISEC and their beliefs about the PISEC program (e.g., "What does being a UE mean to you?"); (ii) we reminded UEs of the definitions of the modes, showed them their presemester survey responses, and asked them to reflect on their answers then as well as how their opinions might have changed since the start of the semester; (iii) we showed the UEs a few clips of their own teaching in PISEC and, for each clip, asked them questions about both their reflections on their teaching and their thoughts on which mode or modes they thought they employed in the clip.

This "stimulated recall" technique was modeled after Spike et al., who employed a similar technique in analyzing the attitudes and beliefs of teaching assistants [40-42]. While the present work primarily deals with the manner in which UEs enact the pedagogical modes in PISEC, rather than their beliefs and attitudes about PISEC, these stimulated recall segments did serve a validation purpose here: UEs' self-assignments matched ours, both suggesting that our coding scheme for the modes is intelligible and communicable to UEs and lending confidence to our own assignments. Deeper analysis of these interviews will be presented in a future work looking at UEs' beliefs and attitudes about PISEC and the effect those factors have on their pedagogy.

\section{B. Cultural-historical activity theory}

As mentioned above, the ideas of activity theory originate with Vygotsky [18] and have been refined and expanded upon since the theory's inception. Vygotsky's "mediated action," and, later, activity theory [32], considered the means and methods (mediational means or tools) by which an agent or agents, the subject, directed their activity toward an object. In the sociocultural model that informed activity theory, this mediated engagement with the object or world is the mechanism of all higher-order cognition. Work by Engeström and others [37,43,44] extended Vygotsky's mediated action triangle to account for the subject's placement within a sociopolitical system within which their activity is mediated not only by the tools they use but also by the rules, community, and division of labor negotiated either explicitly or implicitly in the system. In activity theory, the activity system is the fundamental unit of analysis and is often depicted by an "activity theory triangle," as already depicted in Fig. 1.

For example, in the context of this study, we take the UE as the subject, with the community being formed by the UE and their students. The group members mediate their engagement through shared language, writing and drawing, experimental equipment, and other tools, as dictated by the rules, both of the program itself and those enacted within the group specifically, and the division of labor struck within the group. The UE, in concert with the students, directs their activity toward an object, either a concept or phenomenon or a goal or intention (the latter is commonly also described as an objective). In this study, we follow the methodology of Ref. [33] in using the former interpretation of the object, diverging from Hinko, whose operationalization of the term leaned closer to that of an objective. This definitional choice is also in part due to Hinko's observation, as mentioned above, that UEs operating in the same pedagogical mode-which in Ref. [12] is denoted by activity directed toward the same object (see again Table I) - may nevertheless reflect different objectives in their pedagogy. The salience of this distinction will become more explicitly apparent in the articulation of our expanded model in Sec. VA 2.

More detailed information on activity theory and methods can be found in Refs. [33,36,37,45,46]. 


\section{RESULTS}

\section{A. Stated and enacted UE preferences}

In line with the results presented in Ref. [13] (and, again, the observation that made these UEs salient for this study), all six UEs studied for this work exhibited a pre-posttraining preference shift among the modes (here and following we will use the initialization of both solo and mixed modes, e.g., "solo-P"): either a shift toward a more "active" preference, e.g., from solo instruction (solo-I) to solo consultation (solo-C); or a shift to a broader mindset, e.g., from solo-P to ICP mixed, or both. These shifts were similar to the overall shifts of the population of UEs described in Ref. [13]. The pretraining, post-training, and postsemester stated pedagogical preferences of all six UEs are reported in Table II, along with the enacted pedagogical preferences of each UE as determined through CHAT analysis and the overall aggregated enacted preference numbers.

Overall, we observed an overall broad agreement between the enacted pedagogy of our six UEs and the reported results of Ref. [12] - the pedagogical mode enacted most frequently was consultation (C, 68/129, 52.7\%). By comparison, Hinko reported a consultation mode preponderance of $57 \%$. We similarly observed relatively lower amounts of instruction (I) and participation (P) modes, $8.5 \%$ and $18.6 \%$, respectively, compared to $18.2 \%$ and $24.2 \%$ in Ref. [12]. Dissimilar from Hinko, however, we found an appreciable number of pedagogical events where UEs engaged in pedagogy characterized by mixed modes - that is, events where the UEs' activity, as analyzed using CHAT, demonstrated activity characteristics of multiple modes simultaneously. These novel manifestations of blended modal characteristics are distinct from simple shifts between categorical modes as defined by Hinko. The mixed mode we observed the most frequently was consultation-participation (CP) mode $(14 / 129,14 \%)$, followed by instructionconsultation (IC, 10/129, 7.7\%) and instruction-participation $(2 / 129,1.5 \%)$. We did not observe any examples of UEs utilizing all three modes in mixture during their pedagogy.

We note that Table II also shows a discrepancy between UEs' stated post-training preferences and their enacted preferences. While five of the six UEs expressed a preference for pedagogy involving participationlike components, only one UE of the six utilized any combination of participation-inclusive modes (CP, P, IP, and ICP) a majority of the time, and four of the six UEs utilized soloconsultation mode for more than $60 \%$ of their observed pedagogy. Interestingly, these enacted preferences were observed as early as the first week of PISEC teaching, demonstrating that the shifts in UEs' stated preferences among the modes recorded in the post-training surveys apparently do not persist even into the start of their actual teaching. By the end of the semester, UEs' stated preferences among the modes mostly mirrored their pretraining preferences: four of the five UEs surveyed expressed either a solo- $\mathrm{C}$ or a $\mathrm{CP}$-mixed modal preference and only one expressed a preference for "participation" mode (although see Sec. IV C for a discussion of UEs' perception of their own preferences).

\section{B. Modal prevalence, consistency, and shifts}

Although we found greater variance in UE modes, including the observation of mixed modes of pedagogy, our results broadly corroborate those reported in Ref. [12]: UEs engaged predominantly in consultation mode with lower rates of engagement in other solo modes (the appearance of mixed-modes is entirely distinct from Hinko). Figure 3 shows the relative percentages of each pedagogical mode observed throughout our UEs' teaching. We also looked at each UE's modal consistency over the course of the semester, including by comparing the early, mid, late-semester distributions of each UE's enacted pedagogy among the modes to determine whether any shifts occurred in common (e.g., whether UEs shifted broadly toward participation mode over the semester, as their responses from the post-training survey might indicate a propensity for). Table III shows the modal consistency of each UE over the semester. In line with the findings of Ref. [12], we did observe that UEs tended to gravitate toward a specific mode (five of the six UEs observed engaged in their most-frequent mode at least twice as often as the next-most-frequent mode); however, we also observed more shifts between modes over the course of the semester than Hinko, finding most UEs to engage in multiple modes in the course of a single activity as well as shifting between modes over the semester.

However, there was no single pedagogical trend shared across UEs throughout the semester. For example, Angela and Gabriel's late-semester pedagogy evidenced more

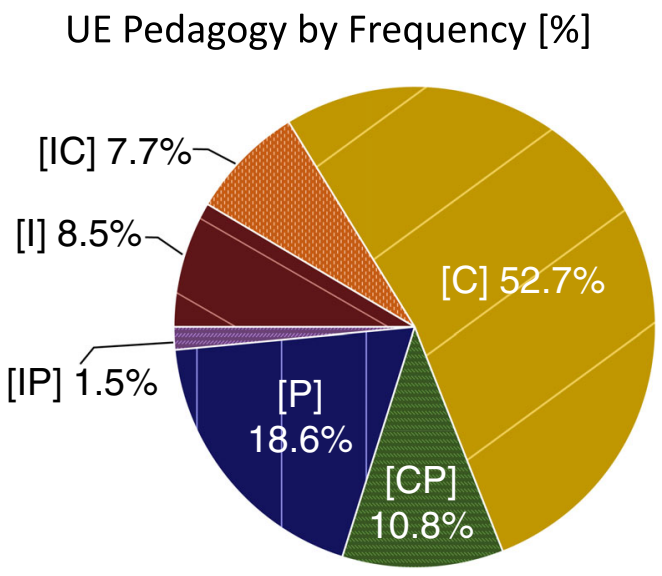

FIG. 3. Percentage prevalence of each pedagogical mode we observed. Similar to Ref. [12], we observed a majority of pedagogy to involve consultationlike techniques, but did observe occasions of the other modes. 
TABLE III. Modal consistency of UEs throughout their early-, mid-, and late-semester observations. As mentioned, there is no singular trend that all UEs follow throughout the semester.

\begin{tabular}{lccccccc}
\hline \hline Pseudonym & & I & IC & C & CP & P & IP \\
\hline Angela & Early & 1 & 0 & 4 & 0 & 0 & 0 \\
& Mid & 2 & 0 & 6 & 0 & 0 & 0 \\
\multirow{4}{*}{ Gabriel } & Late & 0 & 0 & 3 & 1 & 3 & 0 \\
& Early & 0 & 0 & 5 & 1 & 1 & 0 \\
& Mid & 1 & 0 & 9 & 0 & 0 & 0 \\
\multirow{3}{*}{ Moira } & Late & 0 & 0 & 3 & 2 & 4 & 0 \\
& Early & 0 & 0 & 7 & 0 & 0 & 0 \\
\multirow{4}{*}{ Jesse } & Mid & 0 & 0 & 4 & 3 & 1 & 0 \\
& Late & 3 & 0 & 7 & 1 & 2 & 0 \\
\multirow{5}{*}{ Jack } & Early & 0 & 0 & 1 & 0 & 3 & 0 \\
& Mid & 0 & 1 & 2 & 0 & 5 & 1 \\
& Late & 3 & 0 & 1 & 3 & 0 & 0 \\
\multirow{5}{*}{ Winston } & Early & 0 & 1 & 0 & 0 & 0 & 0 \\
& Mid & 0 & 0 & 3 & 1 & 1 & 0 \\
& Late & 0 & 4 & 0 & 1 & 3 & 0 \\
& Early & 0 & 2 & 6 & 1 & 0 & 0 \\
\hline \hline
\end{tabular}

participationlike teaching (both $\mathrm{CP}$ and $\mathrm{P}$ modes), whereas Moira, Jesse, and Jack's late-semester pedagogy shifted toward instructionlike pedagogy (both I and IC modes); Winston stayed largely in C-related modes. Interviews with Angela, Moira, and Jesse led us to believe that these shifts may have been largely caused by emergent factors, rather than large-scale trends in disposition. In the following excerpt from her interview, Angela reflects on the pedagogical mode she employed in an experiment wherein her students attempted to create a Rube-Goldberg device to open a door. She notes that many of her pedagogical moves were influenced by an authentic disconnect between her understanding of her group's goals and the students' activity:

Angela: And I feel like most of the time I am in participation mode. Again, I'm using the word 'we' a lot. But another thing that I think is evidence of that is, I am legitimately asking questions. This whole [RubeGoldberg machine] idea came from them, to begin with, and I don't really understand how it's going to work. It doesn't make sense to me but we're just going with it. And so at one point, somewhere around two minutes, I say, 'My question is how are we going to get the ball to fall,' or something like that. And that's a legitimate question, like I don't understand.

Interviewer: It's not like a 'teacher question'?

Angela: Right.

Interviewer: It was like, 'Please explain to me-'

Angela: Yeah, 'Please explain to me how this is going to work.' And then again around 3:10 I said like, 'What if we have the bucket in this position already.' I think that was another moment where I'm actually trying to figure it out, like, how are we going to accomplish this thing that they want to accomplish... And it's definitely more participation [mode]. I am there, with them, trying to figure out how to get the door to open.

While the factors that influence UEs' enacted pedagogy is not the explicit focus of this study, emergent factors such as those elucidated by Angela (in-the-moment confusion at students' activity, uncertainty about how to meet student goals, etc.), as well as prior influences such as UEs' experiences in formal pedagogy training environments, will be discussed in a future work.

\section{UE perceptions of their own modal preferences}

A significant portion of this study involved recording UEs' own thoughts on the nature of both the pedagogical modes and their own pedagogy in PISEC, through both survey and interview. As mentioned above, we observed discrepancy between UEs' stated and enacted preferences. We also observed a discrepancy between UEs' enacted modalities and the modalities they thought they were utilizing while teaching. Gabriel, for example, only engaged in solo participation mode in five out of 26 events, and in CP-mixed mode only 3 times, compared to a majority usage of solo-consultation mode $(17 / 26,65 \%)$. However, in his end-of-semester survey, Gabriel's retroactive assessment of both his modal preferences and the impact or outcome of those preferences did not match his actual teaching: "I found a mix of consultation and participation to be the best in this setting. This approach lead [sic] to the students having more fun, making it easier to keep them [the students] on track." Interestingly, Gabriel apparently sees in the above quote the "fun" aspects of his interpretation of his pedagogy as a means to achieve his objective of keeping the students "on track"-an objective not associated in Ref. [12] with participation mode.

Angela, similarly, expressed in her postsemester survey: “... I find that consultation and participation modes are most valuable for my interactions with the students, and these two approaches gives students autonomy over the experiments they design and the ideas they come up with." As reported in Table II, Angela's enacted pedagogy counts for solo-C, CP-mix, and solo-P modes were 13, 1, and 3, respectively.

Winston, especially, demonstrated a stark dissonance between self-assessment and actual pedagogy, particularly in his expressed understanding of his "favored" mode: "I found that participation was the most useful. I think this was because after we performed the experiments and entered into occasional discussion phases, I could working [sic] through different ways of thinking about the experiments with them and at times nudge them in the right direction without being the forceful authority." 
This description, focused on moments of discussion where students are "nudged" toward the "right direction," is highly commensurate with consultationlike pedagogy, which Winston was observed to employ a vast majority of the time. By comparison, only 3 times out of 21 total events was Winston observed to engage in pedagogical modes involving any form of participation. Clearly, Winston's understanding of "participation" modal teaching diverges from the definition of the mode as it was taught in the presemester training.

We note that all three UEs who evidence this dissonance between self-assessment and enacted pedagogy did so in a manner that showed their reflective conceptions of their own pedagogy were more "participationlike" than they actually were. All three UEs expressed a belief that they had made good use of some form of participation mode, even though all three UEs had engaged predominantly in consultation mode and, in some cases, only scantly in any participation-related mode. As mentioned above, when UEs were prompted with video of their own pedagogy and asked to assess it, their assessments of singular events matched ours. Similarly, in their surveys and interviews, UEs frequently demonstrated thoughtful, reflective responses about the program and their own pedagogy. We therefore consider the possibility that, rather than evidence of a deficiency in UEs' self-assessment ability or in their "theoretical" understanding of modal characteristics, their conception of the modes is not robust enough to support moment-to-moment reflection throughout the semester or accurate reflection at the end of the semester. This finding is supported by the preliminary findings of Ref. [38].

\section{Expanding upon observations of modal preferences}

\section{Inequitable implementation of modes}

We observed in various UEs' enacted pedagogy a number of novel implementations of the modes reported in Ref. [12]. While, nominally, participation-mode pedagogy is characterized by a direction of activity toward shared, partnerlike engagement, multiple UEs were observed to engage in a form of participation mode favoring a partnership with a specific student, at the seeming expense of other students' engagement. Angela, Gabriel, Jesse, and Winston were all observed to engage in this "inequitable participation mode." In the following excerpt, for example, Gabriel (G) essentially centers the activity-designing a Rube-Goldberg-like device, where students use different components such as balloons, marbles, books, etc., as they see fit - around the engagement of one student (S1), who has taken on a more assertive "leadership" role within the group, while mostly ignoring the engagement of the group's other students (S2, S3, S4).

S1 [to G]: I put a little bit more weight in it.

[S2 approaches the group, walks away after a few seconds of not being spoken to]
G [to S1]: All right, let's see if that'll-I don't think this is gonna pop the balloon.

S1 [to G]: All right, give it a little nudge.

[ $G$ and $S 1$ begin working on the experiment in silence.

S3 approaches the experiment with a spool of fishing

line, begins watching over SI's shoulder but is not spoken to]

G [to S1]: Did we already have it with, have a set of scissors that were set up like this?

S1: But how are we gonna-we're gonna have to have aG [interrupting]: Yeah, have a marble set up or something like this?

[S3 continues to stand behind S1, watching over his shoulder-still without saying anything or being spoken to]

S1: Yeah, but if a marble hits it-here, let me just show you [G]-if a marble hits it, it's only gonna be like... [demonstrates]

G: Now it's slowly leaking.

S1: Now it's slowly leaking.

[S3 leaves the group. S4 walks up and watches over S1's shoulder. S1 and $G$ continue to work on the activity without speaking to others]

This excerpt does evidence many characteristics of participation mode: Gabriel and S1 engage in highly collaborative work on the experiment; Gabriel does not give directives (as he would in instruction mode) and S1 does not ask Gabriel for approval or confirmation (as would happen in consultation mode); neither participant is positioned as an "authority," and the focus is on the experiment itself. However, throughout the excerpt, Gabriel engages exclusively with $\mathrm{S} 1$, even though $\mathrm{S} 2, \mathrm{~S} 3$, and $\mathrm{S} 4$ all approach the group, and S3 even apparently attempts to engage via the use of an artifact (fishing line). All three students are ignored by Gabriel and S1, leading to our description of this participation mode implementation as "inequitable participation."

Angela was also found to engage in such inequitable participation pedagogy. In her interview, Angela was shown a clip of this pedagogy and asked to reflect on it. When asked whether she thought she engaged with all of her students in the clip (we did not use the term "inequitable" at all in the interview), Angela acknowledged that she did not engage with all three students. In fact, she went further to explain the decision by drawing on her experience over the semester with that group of students, one of whom tended to engage with the group mostly in a social manner, if at all. Angela acknowledged

Interviewer: Would you say that you tried ... would you say that you engaged in participation mode with [the particular student]?

Angela: I would say not in this clip. So in the first clip we watched, this is the student I was thinking of who is sometimes isolated. And so in the first clip, my goal was 
to have everyone involved. And I know that, generally, for the whole semester it was a struggle to get themusually, it was her who was kind of goofing off and not really participating, but sometimes it would be a different-usually there was four of them. So I think in this particular clip I had sort of given up on, like she's not...

Interviewer: Like on a 'meta' level?

Angela: Yeah, she will participate when she wants to, and this one student really has an idea of what we should do, and we should... just kind of go with it to get something done rather than spend all our time trying to say 'well, what do you think? What do you think?' And just sort of take something and go with it. And then when she's interested she'll participate. I'm guessing that was my thinking in this particular moment.

\section{UEs "overriding" student objectives}

We also observed incidents where UEs' objectives for pedagogy "overrode" students' own articulated objectives, either situations where UEs tried to "force" a particular form of engagement, or where their own personal scientific interest seemingly drove their engagement at the expense of student engagement. Naturally, such pedagogy runs counter to both PISEC's overall pedagogical philosophy and the explicit definitions of the pedagogical modes of Ref. [12]. We observed several examples of this with the UE Winston but also observed examples of this type of pedagogy in Jack and Gabriel. We observed this behavior exclusively in situations where CHAT analysis determined a modal preference for instruction or consultation mode (that is, we did not see examples of UEs overriding student objectives when engaged in participation mode).

A particularly striking example occurred where the UE Jack's students all decided to engage in a competition to see who could go without speaking the longest.

Jack, who had previously been utilizing almost exclusively consultation-participation mixed pedagogy, began to implement more authoritative, instructionlike techniques, and doing so largely without seeking to secure the engagement of his students. Jack began to ask more and more frequent pedagogical questions-and then immediately answer them himself, expositing on the nature of the experiment without waiting for students to respond even nonverbally. Jack completely took over manipulation of the experiment and continued to manipulate it toward completing the activity, even during an instance where every single one of his students got up and left the table. Additionally, when asked by a nongroup student, "Do you even like this game ... the silence game?" Jack quickly answered, "No, I don't know why they're doing it." We coded Jack's pedagogy during this incident as IC-mixed mode, as Jack leveraged both direct and indirect methods to try and get students to focus on the scientific nature of the experiment. In this and in other cases (for example, we observed Winston getting "wrapped up" in the activity and essentially ignoring his students to discuss the physics of the experiment with another mentor), the UE's activity was observed to be directed toward the experiment itself, their activity seeming to indicate a personal scientific objective rather than an objective of collective engagement and understanding.

Even before considering the interplay between our data and the 2016 pedagogical modes model as presented in Ref. [12], these results suggest that our presemester training has almost no lasting effect on the actual enactment of UEs' pedagogical tendencies, and little if any effect on their ability to utilize their understanding of the modes to inform or even assess their teaching techniques. Five of the six studied UEs' early-semester pedagogies reflected an enacted preference for either solo-C or IC-mixed modes, implying that their stated shifts in preference after training did not even persist a few weeks into the semester. It appears evident that our current training methods are insufficient for achieving the goals presented in Ref. [12] with respect to the pedagogical modes. New methods, informed by a deeper understanding and articulation of the modes themselves, are needed.

\section{DISCUSSION}

In expanding upon the original model presented in Ref. [12], we focus predominantly on the groups' CHAT components, starting from Hinko's conclusion that pedagogical modes are largely defined by the rules and division of labor employed during the enactment of the pedagogy. Our findings corroborate this conclusion, showing, for example, that instruction mode is largely characterized by the UE being situated in a position of authority (division of labor) and doing the majority of manipulation of the experimental equipment (rules). However, we also found that these CHAT characteristics, as well as the UE's objectives (not the CHAT object), provide points of connection between pedagogical modes, allowing both for shifts that "borrow" characteristics from one mode into another and for full mixing of modes.

We also note, building out from Hinko's observation that UE objectives can mediate UEs' implementation of modes, that all three modes appear to be mediated in this way, and that UEs' objectives for pedagogy can cause different solo modes to appear similar to one another even without adopting shared CHAT elements. These large-scale objectives appear to mediate the UE's activity according to their top-level goals for pedagogy, distinguishing them from the CHAT object objective, which characterize the UE's goals or direction for a particular pedagogical event or activity. Following, we will utilize the term "objective" to refer to these overarching mediating influences, following Hinko's terminology for this construct.

These two novel constructs-mixed-modal pedagogy and the effect of UEs' objectives - are used here to build a 
more comprehensive form of the pedagogical modes model originally presented in 2016. We discuss each new facet and its divergence from the 2016 model in turn, finally coming to an articulation of a more comprehensive, nuanced model for characterizing pedagogy in PISEC and, potentially, other informal learning spaces as well. We also discuss the methodological differences between this study and the 2016 study that supported the observation of these new facets in UE pedagogy and limitations of the present work.

\section{A. Refinement of the pedagogical-modes model}

\section{Mixed modes}

We can consider as a basic example a distinction between whether the UE is positioned separately from the students or not (division of labor) and a distinction between whether the UE only, students only, or both UE and students manipulate equipment (rules). According to Hinko's model, pedagogy where a UE is positioned separate from the students (not necessarily as an authority figure) and leaves manipulation of the experimental equipment to the students would characterize the consultation mode. Participation mode is characterized by pedagogy where both UEs and students manipulate equipment and the UE is positioned as a collaborator, part of the group. Both consultation and participation share a focus on students maintaining "control" of the experiment, although their specific implementation of that trait varies, as the rules and division of labor characterizing the mode mediate each other, leading to the more "hands-off" approach of consultation mode or the more "hands-on" approach of participation.

These two modes form a good basis for refining the model, as we observed the consultation-participation mixed mode most frequently in our analysis. When making decisions about whether UEs were engaged in mixed modes or not, we most often relied on the distinctions and similarities between the modes with respect to these two CHAT components, division of labor and rules.

We observed Moira, for example, engaging in a CPmixed mode, acting as both a collaborator and an advisor to her students within one pedagogical event. In the following excerpt, Moira (M), working with three students on an optical lens track experiment alongside another UE (denoted as "R,"), takes on a participatory approach at the start and end of the event. However, during the middle of the event, Moira is positioned physically apart from the experiment and the students, simply watching them engage with the experiment and, occasionally, the other UE. apart from the moments prompted by students' comments, lets the students engage in the experiment (as consultation mode's division of labor).

[Students S1, S2, and S3 are working on the experiment. Moira is chatting with R.]
S1: Wait, wait, wait... I wanna do solar eclipse, it's gonna be solar eclipse.

M: Oo! About that! [takes aperture attachment out of equipment bag] Do you see it, do you see how this kind of looks like it? You can stick that on, somebody see what that does, if you want!

[S2 takes the aperture and begins to affix it to the optical track]

$\boldsymbol{R}:$ Wait, let's, before we turn it on, what do we think it's gonna look like?

[S2 begins to withdraw the aperture]

M: You can attach it! [makes a gesture toward the experimental setup, encouraging students to attach the piece to the optical track]

[Students, with prompting questions from $R$, play with the experiment for about thirty seconds. Moira is watching from the side.]

S1: Maybe we should put this all the way over here... Ooh, it's working!

M: [leans in] Yeah, maybe you can put a lens on and figure out which one works best.

[Moira picks up the lens and holds it up to her eye]

M: So, you can kinda tell what it's gonna do based on like when you look through it... like this, when I look through it and everything looks... Okay I lied, I can't tell what this is doing.

$\boldsymbol{R}$ : 'Just kidding, I'm blind!'

M: This [adjusts the lens] makes it look bigger, this [adjusts the lens] makes it look smaller and blurry.

S1: [pointing at the lens Moira is holding] Let's do that one!

M: Give it a try! See what's happening!

[Students start manipulating equipment again]

In the event partially transcribed above, Moira's CP-mixed pedagogy is employed seemingly toward the objective of student engagement with and control of the experiment: she encourages the students to manipulate the experiment (even, seemingly, in opposition to R's insistence that they form a hypothesis first) and, when she manipulates the equipment herself, does so toward the end of getting students involved with it ("Give it a try!"). We observed traits similar to those described above in other instances of the CP-mixed mode and posit that shared traits between modes (in this case, the shared focus of consultation and participation modes on students' control of the experiment) can provide the means of both shifting between modes and engaging in blended-mode pedagogy. Table IV shows the CHAT components demonstrated by Moira's pedagogy in the above example, illustrating the blending of components from consultation and participation modes.

Similarly, we observed Winston engaged in a IC-mixed role, blending instruction and consultation traits in a single interaction. In one event, Winston, engaged with two students in an experiment to complete a circuit with 
TABLE IV. A tabular depiction of Moira's enacted mixed consultation-participation pedagogical mode, as described above. Each CHAT element (with the exception of the subject, which is Moira, and the community, which is the same in all modes) is characteristic of either the consultation mode or the participation mode as articulated in Ref. [12].

\begin{tabular}{|c|c|}
\hline \multirow[b]{2}{*}{ CHAT element } & Pedagogical mode \\
\hline & Participation \\
\hline Subject & Moira (UE is always the subject) \\
\hline Object & Student engagement \\
\hline $\begin{array}{l}\text { Mediational } \\
\text { means }\end{array}$ & $\begin{array}{c}\text { Experimental } \\
\text { equipment }\end{array}$ \\
\hline Rules & $\begin{array}{l}\text { UE responds to } \\
\text { student questions }\end{array}$ \\
\hline Community & Students and UE (all modes) \\
\hline Division of labor & $\begin{array}{c}\text { Students direct } \\
\text { activity }\end{array}$ \\
\hline
\end{tabular}

various piece of fruit, was observed to utilize leading questions ("Okay, so what configuration do we have to do to make it [the voltage read on a multimeter] highest then?"

"But doesn't it depend on which lead you put in?" etc.) and to largely leave the manipulation of the experiment to students, often watching them engage without interjecting for an appreciable amount of time. Both of these techniques reflect the rules and division of labor of the consultation mode. However, in addition to the advisorlike positioning, Winston's interjections also frequently took on a more instructionlike quality, both giving directives to the students ("Okay let's try the next step of what they said. Try two batteries in a row.") and expositing on the physical nature of the circuit ("But I think if we want to measure it correctly, there's an indication of positive on this side, say, negative on this side. Here, it's saying - and, and we know that when we measure them, they're sort of labeled, so, for example, the 9-volt [battery] is labeled nine volts, it's not negative nine volts, it's nine volts...). Winston's drive to connect his students' experiment to a content learning outcome of physical understanding of the mechanism of the circuit and his utilization of direct exposition to do so are both demonstrative of the rules of instruction mode, and Winston blends these two modes toward his seemingly overarching goal of content knowledge.

We also observed blending of instruction and participation modes. The observation of pedagogy that blends these two modalities may at first seem counterintuitive-as described in Ref. [12], these two modes appear highly divergent, with instruction characterized largely by UE authority and control, and participation characterized largely by shared authority and group control. However, these two modes share as a CHAT trait the UE's direct engagement with the experiment, and we observed occasional examples of pedagogy that we characterized as IP mixed, where the UE leveraged this trait, shifting between authoritative positioning and collaborative positioning. In one pedagogical event, Jesse (the only UE observed to engage predominantly in the participation mode) and his students attempted to set up a board game that used lasers and mirrors. Jesse began the event in a highly collaborative posture, working with students to try and figure out the rules of the game, but as the students demonstrated more and more confusion and frustration over how to set the board up, Jesse began to offer more and more directives and take more and more demonstrative action himself, shifting back and forth between instruction mode's authoritative division-of-labor UE positioning and participation mode's collaborative positioning while continuing to manipulate the equipment toward the same end. One potential factor mediating this choice of pedagogy is the fact that Jesse and his students chose to begin this activity close to the end of the site visit; Jesse's awareness of the imminent end of the site visit may have influenced his decision to take more and more overt control over the experiment. Again, this and other factors that likely lead to UEs' in-the-moment choices of pedagogical modes will be discussed in more detail in a future work.

This mixed-modal pedagogy, characterized by utilization of CHAT elements from multiple modes during the same event, runs counter to the modes as articulated by Hinko in 2016, as, in Ref. [12], modes are presented as categories defined by the group of CHAT elements associated with them. Our observations instead imply a much more closerly interrelated taxonomy of modes, where UEs can pull CHAT elements from one mode into their pedagogy in another mode, creating mixed modes. This new conception of the modes is depicted graphically in Fig. 4, and an

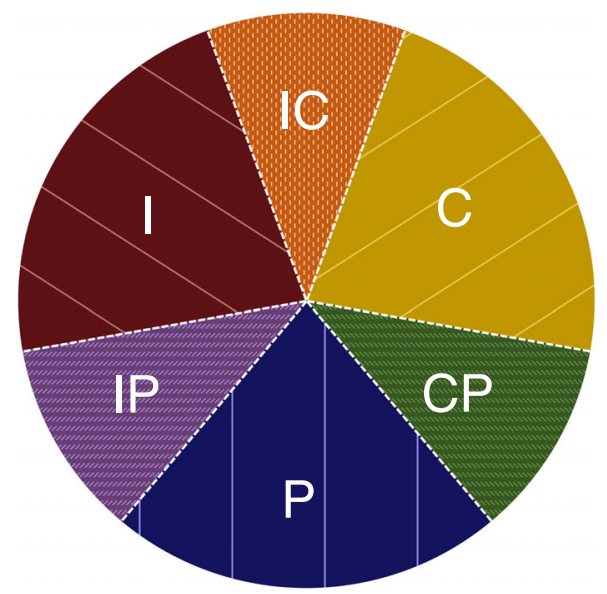

FIG. 4. A revised modal taxonomy that incorporates the observation and existence of mixed-modal pedagogy. Solo modes are patterned with solid stripes, while mixed modes are patterned with dashes. The dotted white lines between modes represent the permeability of modes in this model compared to the 2016 model shown in Fig. 2. 
example of the ways in which CHAT elements from multiple modes are utilized in a single pedagogical event is presented in Table IV.

\section{Expanding on $U E$ objectives}

As reported in Ref. [12] and mentioned above, UEs may direct their implementation of the pedagogical mode toward one or more overarching pedagogical objectives, and those objectives may modify the UE's enactment of a given mode. While analyzing our data, we looked for instances, particularly in examples of consultation-mode pedagogy, where UE pedagogy might imply divergent "process-oriented" and "outcome-oriented" objectives. In fact, we not only found examples supporting Hinko's original findings regarding a split in consultation mode manifestations, we also observed similar process- and outcome-oriented splits in both instruction and consultation modes.

Instruction: We delineated instruction mode from the other two modes in part by whether the "UE acts as an authority figure" (as in Ref. [12]). However, we observed multiple instances where UEs leveraged their authority toward different ends: (i) an outcome-oriented instruction mode where the UE takes on a more demonstrative position and focuses largely on expositing the nature of the experiment and leading students to a correct physical understanding of the phenomena being studied; and (ii) a more process-oriented instruction mode where the UE takes on a more directive role, leveraging their authority toward greater or more "efficient" student engagement with the activity. We differentiate this more process-oriented exploratory instruction mode from, for example, Jesse's abovedescribed IP-mixed mode in part by noting that the UE still retains their position as an authority, rather than acting collaboratively. Pedagogy (i) above aligns most closely with the instruction mode defined in Ref. [12] but we observed both pedagogies (i) and (ii) in our UEs' work.

Participation: We delineated participation mode from the other two modes in part based whether the UEs acted alongside students in "joint construction of activity" (as in Ref. [12]). We observed instances, however, of UEs leveraging their positioning within the group toward different ends, either (i) an outcome-oriented participation, where the UE leverages a sense of shared agency or ownership toward specific ends, acting as a sort of moderator or chairperson; and (ii) a process-oriented participation mode, where engagement is its own end and the UE takes on the role of an equal group member in shared pursuit of consensus-driven group objectives. Pedagogy (ii) is most aligned with the participation mode described by Hinko, but, again, we observed both pedagogies (i) and (ii) enacted by our UEs.

For example, as mentioned above, while we distinguish both process-oriented instruction and outcome-oriented participation modes from IP-mixed mode based on the division of labor and group rules, we observed that all three pedagogical implementations see the UE directing their activity toward efficient operation of the group, leveraging group dynamics (whether collaborative, authoritative, or both) to facilitate smooth group operation. Similarly, in the outcome-oriented instruction and consultation modes as well as the IC-mixed mode (as in Winston's example above), we observed UEs leveraging their positioning within the group to address matters of content or process learning. And, in the more process-oriented consultation and participation modes, as well as in the CP-mixed mode, we observed UEs leveraging students' explicit control over the activity toward implementing a deeper exploration of the activity, whether they were positioning themselves separately from the students or among them.

Using Hinko's original observation of this objectivemediated pedagogy as a foundation for the argument that UE objectives mediate their enactment of the modes, and drawing on our findings that these shifts happen for both instruction and participation modes as well as consultation, we propose an expansion to the pedagogical-modes model that incorporates UEs' large-scale pedagogical objectives (again, what Hinko called "scientific objectives") across all three modes and their mixtures. We propose that these objectives mediate the CHAT elements of a given mode, allowing for distinct modes to nevertheless resemble each other, or for two enacted pedagogies within the same mode to appear distinct. Finally, we posit that these objectives may serve as a driver for shifts among modes.

We might broadly describe these three large-scale objectives as follows:

- Content learning, where the UE drives activity toward a content- or skill-learning goal, closer to a traditional classroom objective. Outcome-oriented instruction, outcome-oriented consultation, and IC-mixed modal pedagogies all appeared to reflect this objective in our observations.

- Engaged exploration, where the UE facilitates students' increased exploration, without necessarily considering any content or comprehension goals. Process-oriented consultation, process-oriented participation, and CP-mixed modal pedagogies all appeared to reflect this objective in our observations.

- Efficient operation, where the UE leverages group dynamics to optimize the group's ability to both set and strive for a goal. Process-oriented instruction, outcome-oriented participation, and IP-mixed modal pedagogies all appeared to reflect this objective in our observations.

We observed that UEs with an overarching content learning objective tended to direct their pedagogy, whether solo-I, solo-C, or IC-mixed mode, toward the outcomes of student understanding and physics knowledge. UEs with an overarching objective of engaged exploration, whether solo-C, solo-P, or CP-mixed mode, tended to direct their 
efforts toward the process of scientific inquiry itself, helping students develop their experimental ability toward any end. UEs directing their activity toward efficient operation seemingly incorporated both process and outcome elements, helping the group set goals and ensuring that the pursuit of those goals was productive.

We note again that these overarching objectives are not meant to produce subcategories within each mode (i.e., we do not claim a hard, categorical boundary between object and process forms of each pedagogical mode based on objective); rather, they overlay the set of modes and allow for (or even cause) shifts between modes. In the entirety of our analysis, we only observed UEs in mixed-mode pedagogy (IC, IP, and CP) directing their activity toward the overarching goal shared by the two solo modes from which the mixed mode was derived. That is, we observed CP-mixed mode pedagogy bent only toward experimental exploration, and never toward content learning or efficient operations, and similar for the other mixed modes IP and IC.

In addition to expanding upon Hinko's original observation of objective-mediated pedagogy through observations in both instruction and participation modes, this articulation of UE objectives argues that said objectives are situated "outside" the modes, as generalized constructs that impact UEs' engagement in both solo and mixed modes. A complete articulation of our expansion on Hinko's original model, including both the incorporation of mixed modes and our proposed inclusion of UE objectives, is depicted in Fig. 5. We further articulate the expanded model in Sec. VA 3.

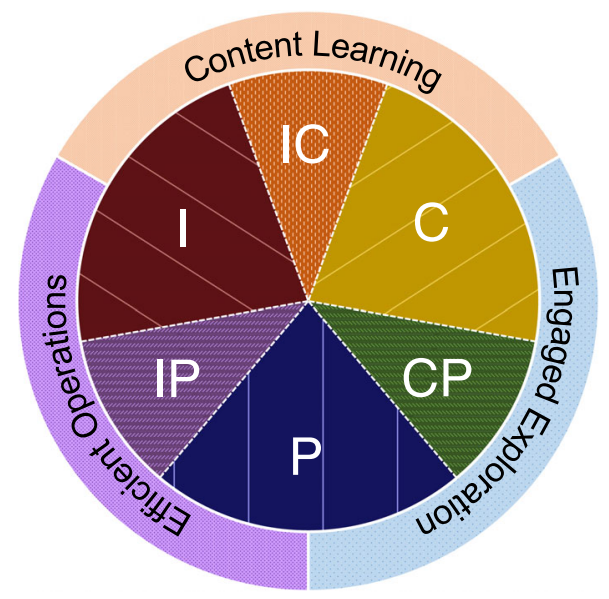

FIG. 5. A depiction of the full modal taxonomy including the three overarching objectives that mediate UEs' pedagogical activity among and within the modes. The inner circle orients the three solo modes and the mixed modes with respect to one another. The outer circle denotes three overarching objectives, each patterned with varying densities of dots, toward which UEs direct their, and their groups' activity, based on their choice of mode and an orientation toward process or outcome. Each objective mediates two solo modes and their shared mixed mode in this model.

\section{A revised modal taxonomy}

Given our observation of mixed-mode pedagogy and our finding that UE objectives mediate all three modes, not just the consultation mode, we propose a model that builds and expands upon the one devised by Hinko. As Hinko does, we argue that modes are largely defined by the group's division of labor and rules; however, we propose that the modes should be considered less as categories exclusively defined by these CHAT elements, and more as clusters of traits described by CHAT elements, such as "UE positions themselves separately from the group," (division of labor) "UE acts as an authority," (division of labor) "UE and students manipulate equipment," (rules) "UE gives directives," (rules) "UE directs activity toward the experiment" (object), etc. We propose that these traits may be shared between and across modes, and that modal mixing occurs when UEs shift along the axis of one or more of these traits, as dictated by the needs of the situation and their overarching objectives.

We also expand upon Hinko's earlier argument that “... scientific objectives are not necessarily specific to any individual mode, although [their presence] does not indicate that all modes are equally suited to all science objectives." We similarly do not see these objectives as fixed categorical traits of the pedagogical modes. Indeed, our observations would seem to indicate that these overarching objectives-content learning, engaged exploration, and efficient operations - are most apparent at points where modes share characteristics. For example, we might infer the efficient operations objectives in situations where both instruction and participation modes (as well as their mixed mode) leverage group dynamics toward "productive" ends.

This expansion upon our conception of UEs' large-scale objectives also builds upon the 2016 model to answer in more detail the question of the ends toward which UEs direct their pedagogy. We argue here that these objectives provide overlaying points of connection between certain modes, facilitating and, potentially, prompting shifts between them. For example, a UE in the consultation mode may direct their action toward developing students' understanding of a physical concept, in line with the content learning (outcome) objective. Satisfied that the students understand, the UE may then "soften" their pedagogical bent, allowing the students to "play" with the experiment in pursuit of their own ends, shifting toward an engaged exploration (process) objective. In pursuit of these goals, the UE's solo-C pedagogy may begin by resembling instruction mode, then shift toward resembling participation mode-all while maintaining CHAT elements of solo-C mode. Or, the UE's pedagogy may fully meld into one or both of the other modes, shifting from an IP-mixed mode to a CP-mixed mode. The UE's pedagogical mode will be evident from the mixture of CHAT elements they utilize in pursuit of their objective. 

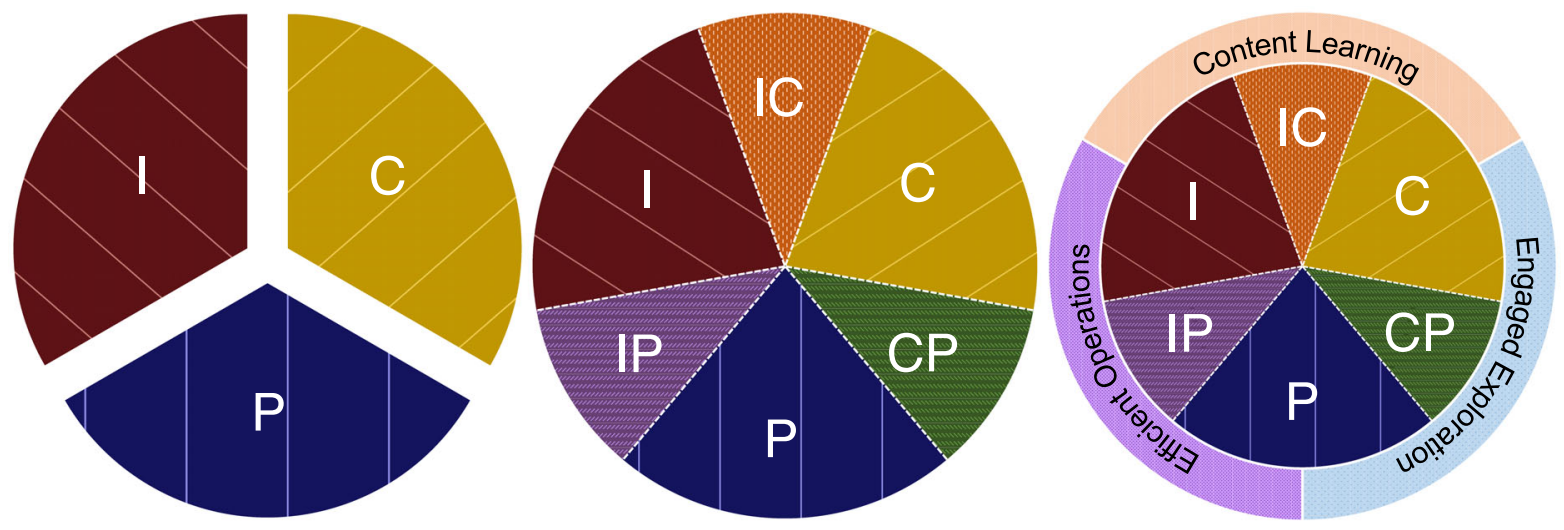

FIG. 6. Summary of the evolution of the pedagogical-modes model as discussed throughout this work: (left) the model as articulated by Hinko, where modes form distinct categories; (center) a mixed-modes model that situates the modes as a neighboring clusters of traits, allowing for blending between them; and (right) the comprehensive taxonomy, with both mixed modes and the overarching pedagogical objectives that mediate UEs' choices among and implementations of the solo modes and their mixed-mode counterparts.

Figure 6 shows the full "evolution" of the pedagogical modes model: beginning with Hinko's 2016 model; adding in the presence of mixed-mode pedagogy and situating the modes as neighboring and sharing traits; and, finally, overlaying UEs' large-scale objectives to create the more comprehensive modal taxonomy for which we argue here. We see this revised model as providing a number of benefits over the original 2016 model. First, we believe that framing the modes as clusters of potentially overlapping traits, rather than as rigid, exclusive categories, facilitates a more nuanced understanding of pedagogy in PISEC from both research and practice perspectives-facilitating UE metacognition about the modes and the means by which they can employ mixed modes, or shift among modes as needed, may help expand their conception of pedagogy in the informal space, going farther toward achieving Hinko's goals of giving UEs “... more confidence in their ability to adapt to new situations at PISEC..." and of working "... with a range of students' behavior." We also believe that the revised model may be more useful for expedient analysis of UE pedagogy (or the pedagogy of instructors in other informal education programs, see Sec. VI). A methodology analyzing the traits of UE pedagogy rather than holistically deconstructing each pedagogical moment may be able to facilitate the development of, for example, an observation protocol geared specifically to the unique, fluctuating environment of PISEC or other informal learning spaces.

The expansion from the 2016 conception of UEs' overarching objectives and the incorporation of the pedagogical objective construct into the model is also important, as instructor objectives are, of course, of key import in both formal and informal spaces alike. Articulating the ends toward which UEs direct their activity helps make apparent their stances toward the purpose not only of their own pedagogy but of PISEC in general; this may allow our three articulated objectives, in the context of an informal learning environment like PISEC, to function similarly to the familiar formal-space construct of epistemic stance or frame. This point of connection, and the ability to help UEs reflect on their objectives for students, will likely help facilitate a more holistic understanding both among UEs and among program researchers of the emergent and preexisting factors that influence UEs' pedagogical methods.

Finally, we note again that the present work was built out of an attempt to address the charge in Ref. [12] to "make these modes salient in UE preparation, that is, to make the roles, rules, and objectives of the activity system explicit." While we agree with Hinko that "each mode has both affordances and limitations and may be more or less suitable depending on local circumstances," rejecting "a hierarchy of modes that are either 'good' or 'bad' at achieving [PISEC's] goals," we note that, in practice, the presentation of the modes as distinct categories tends to encourage UEs to place them in a hierarchy anyway (see, for example, our report in Ref. [38]—Moira says explicitly in her interview that she had put the modes into a hierarchy despite our insistence to the contrary when presenting them).

Our previous model of the modes was clearly insufficient for aligning UEs' stated beliefs with their enacted beliefs, or for making them aware of their epistemological stances in PISEC. This presentation of the modes, their shared traits, and their overarching objectives may more easily accomplish the preparatory goal of Ref. [12]. We also believe that this new model is more likely to be applicable to other informal learning environments, as they focus less on specific instantiations of pedagogy (as the original formulation of the modes did) and more on the traits and techniques employed by the instructor.

\section{B. Comparison of present work to Hinko and limitations}

Because the present work draws directly from both findings and methods in Ref. [12], we discuss the ways 
in which the present work diverges from and builds upon that effort. Of course, the results of the present work expand upon those results, as discussed above.

As mentioned above, we note that the major distinction between Ref. [12] and the present work is the latter's more microgenetic approach. What we mean here is that, using the start and stop criteria detailed in Sec. III A to define the events that formed the grain size of our analysis resulted in each PISEC session's worth of activity producing several such events, which we analyzed independently. Hinko, by contrast, analyzed "rich segments" within a given day's "interaction," but then applied CHAT to the entirety of the interaction. This distinction is not a flaw in Hinko's methodology or a particular improvement of ours. Rather, we argue that the broader lens was likely necessary for articulating the modes in the first place; having the defined modes as a basis freed us to apply them more granularly in the present work.

To test our claim that there is no a priori reason why our methodology should not have produced observations of mixed modes in Hinko's dataset, we obtained a sample of Hinko's data and performed our more granular analysis on it. In one activity's worth of data (which, again, constituted a single "data point" for Hinko), we marked six events using our start-stop criteria. Among those events, we observed four examples of solo-consultation mode, one example of CP-mixed mode, and one example of IC-mixed mode. By comparison, Hinko marked the whole activity as a solo-consultation mode. Again, we argue that the differences here are merely a matter of grain size; "averaging" over the entire day's activity would likely have led us to the same conclusion, as both methodologies utilized CHAT, and the theory does not prescribe a specific quantum of time or thought over which to analyze.

These differences of focus and scale are an important facet of this study's ability to build upon the model originally articulated by Hinko, but we view this study as expanding upon a successful model, rather than as correcting a flawed one. We compare the relationship between the present work and Hinko's work as analogous to repeating an experiment in traditional physics, for example the measurement of energy levels in a nucleus, using a detector with higher energy resolution. Not only may the increased resolution allow for greater precision of known energy levels, unknown-and unsought-levels may arise from the background as a result of the greater precision. The findings of the present work build upon Hinko's findings, but emerged from observations predicated upon our methdology distinctions.

As with any study, we also do not claim that the present work represents the final word on pedagogical techniques in informal spaces. The present work largely addresses the "how" of informal instructor pedagogy- the ways in which UEs employ, navigate, combine, and shift among the original pedagogical modes from Ref. [12], and the motivations that may prompt such activity. However, the study remains largely agnostic to the underlying factors that influence those motivations. For example, in the same interview in which she acknowledged putting the pedagogical modes in a hierarchy despite our explicit encouragement to the contrary, Moira also acknowledged that this choice, as well as some of her early pedagogy in PISEC, was heavily influenced by a learning assistant [8] pedagogy course she was taking concurrently with her volunteer work. The present work has made no attempt to untangle the ways in which emergent factors, such as student behavior, mood, or interest, interface with any a priori expectations or attitudes UEs may have about teaching in PISEC - or the ways in which these factors might impact their objective or choice of mode.

Because the original motivation for the present work was to investigate how incorporating Hinko's suggestion of training on the pedagogical modes impacted volunteer pedagogy in PISEC, we opted to study UEs who (i) participated in training and (ii) took both pre- and post-training surveys. While that sample proved sufficient for focusing, as stated, on the mechanisms of UEs' enacted pedagogy, we acknowledge that an investigation into the motivations underlying UEs' instruction in PISEC would benefit from a broader, more diverse sample. For this study, five of the six UEs studied were first-time volunteers in the program (although one had several years' worth of PISEC experience at the time of study), and no effort was made to purposely diversify demographics among the UEs studied; future efforts will be strengthened by attending to not only UE experience levels but also backgrounds, gender, ethnicity, etc.

These limitations combine to form potential answers to an interesting question: why did we not observe an ICPmixed mode (that is, a mode simultaneously encompassing traits from all three solo modes)? One simple answer is simply that such a mode is likely rare, in the same sense that each mixed mode we observed was rarer than its composite solo modes, and a larger dataset might uncover it. It may also be the case that such a mode requires more "advanced" conceptions of pedagogy than our sample UEs had (although the veteran UE also did not demonstrate ICPmixed pedagogy). Or, it may be the case that our start-stop criteria and CHAT techniques are inappropriate for discriminating between shifts among two modes and shifts among all three simultaneously, at least not without utilizing our articulated objectives as a starting point. Future studies may be able to produce an even finergrained image of UE pedagogy, just as they may be able to provide a broader-scope picture of their pedagogical motivations in informal spaces.

\section{CONCLUSIONS AND FUTURE WORK}

Ultimately, we see this new, revised model as a more complete articulation of UE pedagogy in PISEC, 
leveraging the inroads made by the original model to develop a more comprehensive picture of the ways in which UEs utilize their group positioning, expertise, and goals to facilitate student engagement. As described above, a natural extension of this work would be to more deeply analyze UE interviews and survey data to investigate the factors that influence the pedagogical nuances described here. One particularly intriguing result from the present work is the observation that, in addition to mismatches between post-semester self-assessment of their pedagogy and their actual instruction methods, UEs' enacted modal preferences diverged from their stated or intended modal preferences, as observed on the post-training surveys, even as early as the first week of PISEC activity. One potential implication here, hinted at in Moira's acknowledgement of the influence of her LA training on her PISEC pedagogy, is that external factors, including those that may influence UEs' objectives, may override what they learn in training (see Ref. [38] for a more detailed discussion). A future study investigating these factors will likely allow for both deeper insight into the interplay between formal and informal instruction preparation, but an improved model for training within PISEC itself.

As discussed above, we note that the model may as yet be incomplete. However, the present work provides not only a corroboration and confirmation of the validity of Hinko's original formulation of the modes, but a meaningful improvement of and expansion upon the model that can be used to inform not only future efforts to characterize UE pedagogy in informal spaces (for example, through the creation of observation protocols that may obviate the need for in-depth, moment-by-moment CHAT analysis), but, potentially, efforts in other contexts as well. A straightforward initial outbuilding could be made by performing a similar study on a program that already closely resembles PISEC-one such 5D-informed program exists at California State University San Marcos [47,48]. Such a study could leverage the new formulation of the modes to determine whether instructors engage in similar styles of pedagogy, particularly the extent to which their objectives align or not, and the extent to which their activity is characterized by similar traits (that is, whether the model is even applicable in this context). We also note the existence of formal pedagogy models or environments, such as the studio physics model $[49,50]$ or the Physics through Evidence; Empowerment through Reasoning (PEER) model [51], whose inquiry-based, facilitative implementation may be similar enough to PISEC to allow for a test of the pedagogical modes model in a formal setting. One of the questions posed in Ref. [12] is the extent to which the modes might inform instructor preparation or implementation in formal settings-particularly, similar settings such as these could provide a fruitful venue for a first foray into applying the model to formal pedagogy.

With the identification of the three large-scale objectives, we have already uncovered a means of interpreting UEs' pedagogical choices and understanding the factors that influence those choices-in this case, their large-scale goals for group activity. However, as demonstrated briefly above, for example, in the sample from Angela's interview, a number of emergent, microgenetic factors also likely play a role in UEs' moment-to-moment pedagogical choices. Preliminary analysis on this topic [38] indicates that UEs' teaching experiences in formal settings may influence and, at times, override preparation they receive for teaching in PISEC. Further analysis is ongoing and a more detailed study of these factors is forthcoming. Understanding the factors that influence UE pedagogy, as well as the techniques and objectives that guide their instructional implementation, will help us create a training paradigm that prepares volunteers to more easily facilitate student engagement and agency, more easily attending to the full breadth of facets of science learning [6]. This in turn could lead to a more effective means of understanding and conducting public engagement in the physics community and, potentially, the formal classroom as well.

\section{ACKNOWLEDGMENTS}

We gratefully acknowledge the participation of the local community education partners in the PISEC program, as well as the university students who volunteered their time and effort as UEs. We also extend heartfelt thanks to Professor Kathleen Hinko for discussions on the revisions and the revised model. This work is supported by the JILA NSF Physics Frontier Center (NSF PHY-1734006) and STROBE (NSF DMR-1548924), as well as by NSF Grant No. DRL1713060. We also thank Dr. Alexandra Lau for reading the manuscript and providing insightful feedback prior to submission. Any opinions, findings, and conclusions or recommendations expressed in this material are those of the author (s) and do not necessarily reflect the views of the National Science Foundation. 
[1] APS outreach guide.

[2] National Science Foundation, Building the Future: Investing in Discovery and Innovation-NSF Strategic Plan for Fiscal Years (FY) 2018-2022 (National Science Foundation, Washington, DC, 2018).

[3] A. V. Maltese and R. H. Tai, Eyeballs in the fridge: Sources of early interest in science, Int. J. Sci. Educ. 32, 669 (2010).

[4] K. P. Dabney, R. H. Tai, J.T. Almarode, J. L. MillerFriedmann, G. Sonnert, P. M. Sadler, and Z. Hazari, Out-of-school time science activities and their association with career interest in stem, Int. J. Sci. Educ., Part B 2, 63 (2012).

[5] N. Finkelstein, Context in the context of physics and learning, in Proceedings of the 2001 Physics Education Research Conference, Rochester, NY, edited by K. Cummings, S. Franklin, and J. Marx (AIP, New York, 2001).

[6] P. Bell, B. Lewenstein, A. W. Shouse, M. A. Feder et al., Learning Science in Informal Environments: People, Places, and Pursuits (National Academies Press, Washington, DC, 2009).

[7] E. Etkina, Helping graduate assistants teach physics: Problems and solutions, J. Grad. Teach. Assist. Develop. 7, 123 (2000).

[8] V. Otero, S. Pollock, and N. Finkelstein, A physics department's role in preparing physics teachers: The Colorado Learning Assistant Model, Am. J. Phys. 78, 1218 (2010).

[9] L. McDermott and P. Shaffer, The Physics Education Group at the University of Washington, in Tutorials in Introductory Physics (University of Washington, Seattle, WA, 1992).

[10] L. C. McDermott and E. F. Redish, Resource letter: Per-1: Physics education research, Am. J. Phys. 67, 755 (1999).

[11] R. R. Hake, Socratic pedagogy in the introductory physics laboratory, Phys. Teach. 30, 546 (1992).

[12] K. A. Hinko, P. Madigan, E. Miller, and N. D. Finkelstein, Characterizing pedagogical practices of university physics students in informal learning environments, Phys. Rev. Phys. Educ. Res. 12, 010111 (2016).

[13] M. B. Bennett, K. Hinko, B. Fiedler, and N. Finkelstein, The effect of explicit preparation in pedagogical modes for informal physics educators, in Proceedings of the 2017 Physics Education Research Conference, Cincinnati, $\mathrm{OH}$, edited by L. Ding, A. Traxler, and Y. Cao (AIP, New York, 2017), pp. 52-55.

[14] Partnerships for Informal Science Education in the Community.

[15] CU Boulder Physics Education Group website.

[16] JILA Physics Frontier Center-an NSF Physics Frontier Center.

[17] M. Cole, The Fifth Dimension: An After-School Program Built on Diversity (Russel Sage Foundation, New York, 2006).

[18] L. Vygostky, Mind in Society (Harvard University Press, Cambridge, MA, 1978).

[19] K. D. Gutiérrez, P. Baquedano-López, and C. Tejeda, Rethinking diversity: Hybridity and hybrid language practices in the third space, Mind Culture Act. 6, 286 (1999).

[20] K. D. Gutiérrez, Developing a sociocritical literacy in the third space, Read. Res. Q. 43, 148 (2008).
[21] R. Wulf, K. Hinko, and N. Finkelstein, Promoting children's agency and communication skills in an informal science program, AIP Conf. Proc. 1513, 430 (2012).

[22] R. Wulf, K. Hinko, and N. Finkelstein, Comparing mechanistic reasoning in open and guided inquiry physics activities, in Proceedings of the 2013 Physics Education Research Conference, Portland, OR (AIP, New York, 2013), p. 369.

[23] L. M. Mayhew and N. D. Finkelstein, Learning to communicate about science in everyday language through informal science education, AIP Conf. Proc. 1179, 205 (2009).

[24] K. Hinko, J. Seneca, and N. Finkelstein, Use of scientific language by university physics students communicating to the public, in Proceedings of the 2014 Physics Education Research Conference, Minneapolis, MN (AIP, New York, 2014), p. 115.

[25] K. Hinko and N. Finkelstein, Impacting university physics students through participation in informal science, AIP Conf. Proc. 1513, 178 (2012).

[26] N. R. Council et al., Inquiry and the National Science Education Standards: A Guide for Teaching and Learning (National Academies Press, Washington, DC, 2000).

[27] CU Boulder Fall 2019 Census Overall Enrollment Profile.

[28] Collage Construction by Michelle Wittig, from Jonathan Zeledon.

[29] A. C. Barton and K. Yang, The culture of power and science education: Learning from Miguel, J. Res. Sci. Teach. 37, 871 (2000).

[30] A. C. Barton, Science education in urban settings: Seeking new ways of praxis through critical ethnography, J. Res. Sci. Teach. 38, 899 (2001).

[31] C. Fracchiolla, S. Hyater-Adams, N. Finkelstein, and K. Hinko, University physics students' motivations and experiences in informal physics programs, in Proceedings of the 2016 Physics Education Research Conference, Sacramento, CA (AIP, New York, 2016), pp. 124-127.

[32] A. N. Leontèv, Activity, Consciousness, and Personality (Prentice Hall, Upper Saddle River, New Jersey USA, 1978).

[33] Y. Engeström, Non scolae sed vitae discimus: Toward overcoming the encapsulation of school learning, Learn. Instr. 1, 243 (1991).

[34] V. Davydov and L. Radzikhovskii, Vygotsky's theory and the activity-oriented approach in psychology, Lev Vygotsky: Crit. Assess. 1, 113 (1999).

[35] V. Kaptelinin and B. A. Nardi, Acting with Technology: Activity Theory and Interaction Design (MIT Press, Cambridge, MA, 2006).

[36] M. Cole, Cultural Psychology: A Once and Future Discipline (Harvard University Press, Cambridge, MA, 1998).

[37] Y. Engeström, Learning by expanding: An activity, Theoretical Approach to Develomental Research.-Helsinki: Orienta-Konsultit (Cambridge University Press, Cambridge, England, 1987).

[38] M. B. Bennett, B. Fiedler, and N. Finkelstein, What factors influence pedagogical methods in informal learning spaces?, in Proceedings of the 2019 Physics Education Research Conference, Provo, UT (AIP, New York, 2019).

[39] B. Fiedler, C. Fracchiolla, M. B. Bennett, K. Hinko, and N. Finkelstein, A design-based informal physics program 
from a youth perspective, in Proceedings of the 2018 Physics Education Research Conference, Washington, DC (AIP, New York, 2018).

[40] B. T. Spike, An investigation of the knowledge, beliefs, and practices of physics teaching assistants, with implications for TA preparation, $\mathrm{PhD}$ thesis, 2014 (unpublished).

[41] B. T. Spike and N. D. Finkelstein, Toward an analytic framework of physics teaching assistants' pedagogical knowledge, AIP Conf. Proc. 1413, 363 (2012).

[42] B. T. Spike and N. D. Finkelstein, Design and application of a framework for examining the beliefs and practices of physics teaching assistants, Phys. Rev. Phys. Educ. Res. 12, 010114 (2016).

[43] Y. Engeström et al., Activity theory and individual and social transformation, Perspectives on Activity Theory (Cambridge University Press, Cambridge England, 1999), p. 199.

[44] M. Cole and Y. Engeström, A cultural-historical approach to distributed cognition, in Distributed Cognitions: Psychological and Educational Considerations, p. 1 (Cambridge University Press, Cambridge, England, 1993).
[45] H. Daniels, A. Edwards, Y. Engeström, T. Gallagher, and S. Ludvigsen, Activity Theory in Practice (Routledge, Oxon, 2010).

[46] L. C. Yamagata-Lynch, Understanding cultural historical activity theory, in Activity Systems Analysis Methods (Springer, New York, 2010), pp. 13-26.

[47] Center for Research and Engagement in STEM Education.

[48] Mobile Making Program.

[49] J. M. Wilson, The CUPLE physics studio, Phys. Teach. 32, 518 (1994).

[50] R. J. Beichner, J. M. Saul, D. S. Abbott, J. J. Morse, D. Deardorff, R. J. Allain, S.W. Bonham, M. H. Dancy, and J.S. Risley, The student-centered activities for large enrollment undergraduate programs (SCALEUP) project, Research-based Reform Univ. Phys. 1, 2 (2007).

[51] W. E. Lindsay, V. Otero, and S. Belleau, PEER suite: A holistic approach to supporting inductive pedagogy implementation, in Proceedings of the 2018 Physics Education Research Conference, Washington, DC (AIP, New York, 2018). 